\title{
The Relationship of Pre-Clerkship Immature Defense Style in Medical Students with Physician-Patient Interactions
}

\author{
So-Jin Lee, ${ }^{1,2}$ Chul-Soo Park, ${ }^{2}$ Bong-Jo Kim, ${ }^{1,2}$ Cheol-Soon Lee, ${ }^{2,3}$ Boseok Cha,,${ }^{1,2}$ Dongyun Lee, ${ }^{1,3}$ \\ Jiyeong Seo, ${ }^{2,3}$ Jae-Won Choi, ${ }^{1,2}$ Young-Ji Lee, ${ }^{3}$ Yoon Jung Lee, ${ }^{2}$ and Eun-Ji Lim ${ }^{3}$ \\ ${ }^{1}$ Department of Psychiatry, Gyeongsang National University Hospital, Jinju, Korea \\ ${ }^{2}$ Department of Psychiatry, Gyeongsang National University School of Medicine, Jinju, Korea \\ ${ }^{3}$ Gyeongsang National University Changwon Hospital, Changwon, Korea
}

Objectives: The ability of medical students to form positive relationships with patients is influenced by the students' personality. The psychological characteristics necessary for effective physician-patient interactions (PPIs) have not been identified. Methods: In August of 2012, 2013, and 2014, second-year medical students at Gyeongsang National University completed the Korean version of the Defense Style Questionnaire (K-DSQ). Following completion of their 2-year clerkships, the students completed the KDSQ again. Of the 216 second-year students, 187 (94 males and 93 females) aged 24-38 years (mean, 28.9 \pm 2.8 years) completed the K-DSQ at year 4. PPIs were rated by standardized patients during practical examinations following the clerkships. Results: Female sex $(\beta=-0.157, p=0.035)$ and a more immature defense style in year $2(\beta=0.197, p=0.027)$ were significant predictors of better PPIs in year 4 . An increase in humor during the clinical clerkship $(\beta=0.171, p=0.030)$ and female $\operatorname{sex}(\beta=-0.170, p=0.023)$ were significant predictors of the year-4 PPI ratings. Conclusion: Female sex and a more immature defense style in the second year, as well as an increase in humor during clerkships predicted positive PPIs.

Psychoanalysis 2021;32(3):107-111

KEY WORDS: Immature defense style · Humor · Medical students · Physician-patient interactions.

Received: May 6, 2021 Revised: June 14, 2021 Accepted: June 15, 2021

Address for correspondence: Chul-Soo Park, MD, PhD

Department of Psychiatry, Gyeongsang National University School of Medicine, 15 Jinju-daero 816beon-gil, Jinju 52727, Korea

Tel: +82-55-750-8086, Fax: +82-55-759-0003, E-mail: cspark8083@gmail.com

\section{Introduction}

The ability of medical students to form positive relationships with patients is influenced by the students' personality characteristics (Abbiati et al. 2016; Mahoney et al. 2016). During the preclinical period, conscientiousness is important for good performance, while in the clinical period, extraversion, openness, and agreeableness are essential for developing professionalism (Lievens et al. 2009). Extraversion and agreeableness are also important for interpersonal relationships (Abbiati et al. 2016) and appear crucial for effective physician-patient interactions (PPIs). Schreckenbach et al. (2018) found that extraversion together with high emotion recognition, but not extraversion alone, predicted positive PPIs of medical students with standardized patients (SPs). Another study showed that medical students' empathic ability

This is an Open Access article distributed under the terms of the Creative Commons Attribution Non-Commercial License (https://creativecommons.org/licenses/by-nc/4.0) which permits unrestricted non-commercial use, distribution, and reproduction in any medium, provided the original work is properly cited. was not associated with any particular personality traits (Seitz et al. 2018). However, there has been no research on the relationship between the defense styles of medical students and their ability to engage in effective PPIs.

A Danish study found that pseudo-altruism, denial, and undoing were more common among medical students than other types of students (La Cour 2002). Mature defenses were associated with better academic performance; immature and neurotic defenses were associated with poor academic performance (Waqas et al. 2015). Similarly, higher neuroticism was associated with poorer academic performance in Malaysian medical students (Bhagat et al. 2016). However, another longitudinal study reported that high neuroticism at baseline, but not during follow-up, was associated with better academic attainment (Lourinho et al. 2017). This indicates that changes in defenses influenced students' ability to form good relationships with patients.

This study aimed to explore the relationship between the defenses of medical students and their ability to engage in effective PPIs. We explored the defense styles, and underlying mechanisms thereof, of medical students before and after 
clinical clerkship and the relationships of defenses per se and changes in defenses with PPIs. We hypothesized that changes in defense style and/or mechanisms would be related to PPI quality.

\section{Methods}

\section{Participants}

This study is part of a larger research project entitled 'A Study on the PPIs of Medical Students,' which follows a cohort of medical students at Gyeongsang National University (GNU) Medical School throughout their clerkships, and assesses their psychological and sleep-related characteristics with the goal of identifying the factors affecting their ability to form efficient PPIs (Lee 2018; Lee et al. 2019, 2020). At the beginning of August 2012, 2013, and 2014, we described the study in detail to year-2 students $(n=249)$ at GNU Medical School. The process of study recruitment is described elsewhere (Lee et al. 2019, 2020). After rotations in clinical departments, the same students, by then in year 4, completed the questionnaires again in September 2014, 2015, and 2016. Students who did not proceed to clinical clerkships, or who withdrew temporarily or permanently, were excluded. The questionnaires were anonymized, and student identities were managed separately. The data on 148 year-2 students (in 2012 and 2013) were analyzed previously as part of a crosssectional study, which has been published (Lee et al. 2013). We recruited 222 year-2 students, of whom 187 (94 males and 93 females) aged $24-38$ years (mean, $28.9 \pm 2.8$ years) completed questionnaires at year 4 . In year 4 , the students also completed a clinical performance examination performed by the Pugyeong Consortium, who provided the PPI ratings data for this study. Students were divided into three groups by year; group I included 59 students (30 males and 29 females) who were in year 2 in 2012 and year 4 in 2014, group II included 71 students ( 29 males and 42 females) who were in year 2 in 2013 and year 4 in 2015, and group III included 57 students (35 males and 22 females) who were in year 2 in 2014 and year 4 in 2016. The Institutional Review Board of GNU approved this study (IRB file number: GIRB-A14-Y-0051).

\section{Assessments}

The Korean version of the Defense Style Questionnaire (KDSQ) was completed before and after clerkship (Cho 1999). The K-DSQ evaluates 16 ego defense mechanisms and four defense styles using a seven-point Likert scale (range: 1-7) (Cho 1999). The adaptive defense style includes humor, sublimation, omnipotence, and denial. The immature defense style includes consumption, passive aggression, fantasy, splitting, projection, and acting out. The self-inhibiting defense style in- cludes suppression, reaction formation, undoing, and withdrawal. The conflict-avoiding style consists of resignation and isolation. Although the phrasing of K-DSQ items implies that defenses are traits, some defense styles and mechanisms can be viewed as outcomes (Bond 2004). We examined differences between years 2 and 4 in defense mechanisms and styles to identify personality changes associated with clinical clerkship.

PPI ratings were provided by SPs during practical examinations conducted in July by year-4 students. Experienced simulated patients trained in standardized rating techniques rated the medical students based on predefined items, including: "Has a good relationship with the patient at the beginning of the interview," "Listens well to the patient," "Asks questions efficiently," "Tries to understand the position of the patient," and "Explains easily." Each item was rated on a fivepoint Likert scale; total possible scores ranged from 0 to 20 . Each student's PPI was scored six times, once by each of six different SPs. The reliability of the previous PPI ratings was reported to be high: 0.85 in 2012 and 0.88 in 2013 (Kam et al. 2013).

\section{Statistical analysis}

The Kruskal-Wallis test was used to evaluate differences in defense styles and mechanisms among year-groups I-III. Pearson's correlations were calculated between parametric variables, and Spearman's correlations between non-parametric variables. We included variables with significant correlation coefficients as independent variables in multiple regression analyses $(\mathrm{p}<0.05)$. Multiple linear regression analysis was used to define defense styles and mechanisms and changes in these parameters in terms of PPI prediction at year 4 after controlling for student age, sex, and year-group. Another multiple regression analysis was performed to assess only the changes in defense predicting for PPI while controlling for age and sex. All analyses were performed using SPSS for Macintosh software (ver. 23.0; IBM Corp., Armonk, NY, USA), and a twotailed $\mathrm{p}$-value $<0.05$ was considered to indicate statistical significance.

\section{Results}

The Kruskal-Wallis test showed that the baseline personality at year 2 varied by year-group (i.e., groups I, II, and III). The proportions of adaptive $(\mathrm{H}=12.0, \mathrm{p}=0.002)$, immature $(\mathrm{H}=26.5, \mathrm{p}<0.001)$, and self-suppressive $(\mathrm{H}=15.9, \mathrm{p}<$ $0.001)$ defense styles differed significantly by year-group. Humor $(\mathrm{H}=59.5, \mathrm{p}<0.001)$, consumption $(\mathrm{H}=10.7, \mathrm{p}=0.005)$, fantasy $(\mathrm{H}=20.2, \mathrm{p}<0.001)$, splitting $(\mathrm{H}=32.8, \mathrm{p}<0.001)$, projection $(\mathrm{H}=63.2, \mathrm{p}<0.001)$, acting out $(\mathrm{H}=22.9$, $\mathrm{p}<0.001)$, re- 
action formation $(\mathrm{H}=6.2, \mathrm{p}=0.046)$, undoing $(\mathrm{H}=20.34, \mathrm{p}<$ $0.001)$, withdrawal $(\mathrm{H}=13.2, \mathrm{p}=0.001)$, and resignation $(\mathrm{H}=$ $26.1, \mathrm{p}<0.001)$ varied by year-group. Interestingly, year-4 personalities differed less than did year- 2 personalities among the groups; only the self-suppressive $(\mathrm{H}=8.0, \mathrm{p}=0.018) \mathrm{de}$ fense style, and projection $(\mathrm{H}=6.1, \mathrm{p}=0.047)$ and suppression $(\mathrm{H}=6.3, \mathrm{p}=0.043)$ defense mechanisms differed among the year-groups.

The year-4 PPI scores were significantly correlated with the use of several defenses and defense changes from year 2 to year 4 . Both adaptive $(\mathrm{r}=-0.15, \mathrm{p}=0.043, \mathrm{n}=183)$ and immature $(\rho=0.21, p=0.004, n=177)$ defense styles before clerkship were significantly correlated with year-4 PPI ratings. The year2 scores for humor $(\mathrm{r}=-0.17, \mathrm{p}=0.021, \mathrm{n}=183)$, passive aggression $(\rho=0.15, p=0.043, n=183)$, fantasy $(\rho=0.17, p=0.023$, $\mathrm{n}=183)$, splitting $(\rho=0.18, \mathrm{p}=0.015, \mathrm{n}=183)$, projection $(\rho=0.23$, $\mathrm{p}=0.002, \mathrm{n}=180)$, acting out $(\rho=0.24, \mathrm{p}=0.001, \mathrm{n}=183)$, and resignation ( $\rho=0.15, p=0.045, n=184)$ were significantly correlated with PPI. Changes from year 2 to year 4 in adaptive defense style $(\mathrm{r}=0.15, \mathrm{p}=0.046, \mathrm{n}=181)$, humor $(\mathrm{r}=0.19, \mathrm{p}=$ $0.012, \mathrm{n}=182)$, projection $(\mathrm{r}=-0.16, \mathrm{p}=0.037, \mathrm{n}=179)$, and suppression $(\mathrm{r}=-0.15, \mathrm{p}=0.046, \mathrm{n}=181)$ were also correlated with the PPI ratings. Female sex and a more immature defense style in year 2 were significant predictors of better PPIs at year 4 , explaining $8 \%$ of the variance (Table 1 ). In another regression analysis of changes in defense mechanisms, female sex and an increase in humor from year 2 to year 4 were significant predictors of the year-4 PPI (Table 2).

\section{Discussion}

Interestingly, although year-2 personalities varied among the year-groups, the year-4 personalities differed less. Only the use of the self-suppressive defense style and of suppression and projection as defense mechanisms differed among the year-groups. After 2 years of clerkship, the defenses mounted by medical students became similar. This might reflect the influence of environment on psychological development during early adulthood. This phenomenon cannot be explained by the influence of clinical education alone. The effects of clinical training on personality should be investigated more thoroughly, with consideration given to the influences of environment and demographic factors such as marital status, residence type, alcohol consumption, smoking, religion, physical exercise, and club activities.

The ability to form a productive relationship with trained SPs at year 4 was associated with use of an immature defense style at year 2 and with being female. A previous study found that greater neuroticism at the time of admission to medical school was associated with better academic achievement (Lourinho et al. 2017), reflecting the "brightness" of an immature personality. Because doctor-patient interactions

Table 1. Multiple linear regression analysis used to evaluate baseline defenses and changes in defenses during clerkship as predictors of PPI ratings given by standardized patients at year 4

\begin{tabular}{lcccc}
\hline & $\mathrm{B}$ & Standard error & $\beta$ & $\mathrm{p}$-value \\
\hline Intercept & 52.111 & 6.030 & $<0.001^{\dagger}$ & 0.733 \\
Age (years) & -0.061 & 0.178 & -0.025 & $0.035^{*}$ \\
Sex (female=0, male=1) & -2.116 & 0.998 & -0.157 & 0.359 \\
Year-group (I=0, II=1, III=2) & 0.710 & 0.773 & 0.083 & $0.027^{*}$ \\
Immature defense style (year 2) & 1.914 & 0.855 & 0.197 & 0.274 \\
Adaptive defense style (year 2) & -0.919 & 0.836 & -0.099 & 0.199 \\
Humor (difference between years 2 and 4) & 0.522 & 0.405 & 0.127 & 0.041 \\
Projection (difference between years 2 and 4) & 0.254 & 0.610 & 0.678 \\
\hline
\end{tabular}

Dependent variable: PPI rating. $\mathrm{R}^{2}=0.12$, adjusted $\mathrm{R}^{2}=0.08, \mathrm{~F}=3.2(\mathrm{p}<0.05), \mathrm{n}=176 .{ }^{*} \mathrm{p}<0.05,{ }^{\mathrm{t}} \mathrm{p}<0.001$. PPI: physician-patient interaction

Table 2. Multiple linear regression model used to evaluate changes in defenses during clerkship as a predictor of PPI ratings given by standardized patients at year 4

\begin{tabular}{lcccc}
\hline & B & Standard error & $\beta$ & p-value \\
\hline Intercept & 55.265 & 5.056 & -0.023 & 0.753 \\
Age (years) & -0.055 & 0.175 & -0.170 & $0.023^{*}$ \\
Sex (female =0, male=1) & -2.279 & 0.991 & 0.171 & $0.030^{*}$ \\
Humor (difference between years 2 and 4) & 0.695 & 0.317 & -0.118 & 0.133 \\
Projection (difference between years 2 and 4) & -0.724 & 0.480 & \\
\hline
\end{tabular}

Dependent variable: PPI rating. $\mathrm{R}^{2}=0.08$, adjusted $\mathrm{R}^{2}=0.05, \mathrm{~F}=3.5(\mathrm{p}<0.05), \mathrm{n}=179 .{ }^{*} \mathrm{p}<0.05,{ }^{\dagger} \mathrm{p}<0.001$. PPI: physician-patient interaction 
tend to push patients into a dependent-childish relationship to doctors, when a patient regresses in the doctor-patient interaction the immature defenses of patients may emerge (Balint 1986). Greater use of an immature defense style at year 2 implies the reversible nature of immaturity of our medical students, which may be linked to libidinal regression in service to the ego (Arlow and Brenner 1964). Doctors who readily accept immature defenses offered by patients (because the doctors used immature defenses earlier) may establish therapeutic alliances with patients more easily, allowing/encouraging patient dependence.

Increases in humor from year 2 to year 4 improved the formation of stable relationships with SPs; humor signals friendship and protectiveness, encouraging patients to express discomfort frankly (Fenichel and Rangell 1995), and thereby enhancing PPIs. A previous study conducted with Korean medical students reported no significant sex difference in empathic ability (Lee et al. 2009). However similar to previous studies (Hojat et al. 2002; Rezaei and Mehrabani 2014; Berg et al. 2015; Hardeman et al. 2015), we found that females scored higher on PPI evaluations. One study reported this sex difference in year 1 and conveyed concern that the difference would persist (Hardeman et al. 2015); we have now confirmed that the difference indeed endures beyond the preclinical years. This difference is often attributed to sex socialization; boys and girls are reared differently (Garaigordobil 2009; Berg et al. 2015). Some studies found that SPs assess historytaking and physical examination skills more reliably than they judge interpersonal skills (Berg et al. 2011; Berg et al. 2015). However, our SPs were trained to assess students' interpersonal attributes reliably.

Our study had several limitations. First, the influences of environmental factors, and of demographic and health-related characteristics such as alcohol use, smoking, and exercise, were not considered. Future studies considering the potential impact of such factors on personality are needed. Second, the PPI ratings provided by the SPs may not fully reflect the capacity of students to establish therapeutic alliances. However, the SPs were trained, and the same PPI protocol was used in all study years. Third, the DSQ does not measure unconscious defense mechanisms directly, but rather assesses self-appraised conscious derivatives (Vaillant 1992; Cho 1999). The term "defense mechanism" describes "not only an unconscious intrapsychic process but also behavior that is either consciously or unconsciously used to reconcile internal drives with external demands" (Vaillant 1992).

Despite these limitations, our study has several strengths. First, we used a prospective design to assess differences in personality changes among three cohorts of medical students during the clinical practice period. As the capacity for posi- tive PPIs tends to form during the clinical clerkship, it is important to evaluate the relevant factors. Second, to the best of our knowledge, this is the first study to explore the effects of psychological defenses on the PPIs of medical students.

In conclusion, we found that female sex and a more immature preclinical defense style predicted positive PPIs among students undergoing clinical clerkships. Also, an increase in humor was related to improved PPIs.

\section{Acknowledgments}

This research was partially based on the first author's doctoral thesis: The relationship of Defense Changes during Clinical Clerkship with Physician-Patient Interactions, Resilience, and Circadian Preference (Unpublished doctoral dissertation): Gyeongsang National University, Jinju, Republic of Korea, 2018

\section{Conflicts of Interest}

The authors have no potential conflicts of interest to disclose

\section{ORCID iDs}

$\begin{array}{ll}\text { Chul-Soo Park } & \text { https://orcid.org/0000-0003-0530-7960 } \\ \text { So-Jin Lee } & \text { https://orcid.org/0000-0003-2904-9206 } \\ \text { Bong-Jo Kim } & \text { https://orcid.org/0000-0003-2419-7306 } \\ \text { Cheol-Soon Lee } & \text { https://orcid.org/0000-0003-1479-6962 } \\ \text { Boseok Cha } & \text { https://orcid.org/0000-0002-3309-8863 } \\ \text { Dongyun Lee } & \text { https://orcid.org/0000-0002-3977-3663 } \\ \text { Jiyeong Seo } & \text { https://orcid.org/0000-0002-7329-8296 } \\ \text { Jae-Won Choi } & \text { https://orcid.org/0000-0002-4516-1954 } \\ \text { Young-Ji Lee } & \text { https://orcid.org/0000-0003-0201-2518 } \\ \text { Yoon Jung Lee } & \text { https://orcid.org/0000-0003-4208-7039 } \\ \text { Eun-Ji Lim } & \text { https://orcid.org/0000-0003-3967-8524 }\end{array}$

\section{REFERENCES}

Abbiati M, Baroffio A, Gerbase MW. Personal profile of medical students selected through a knowledge-based exam only: are we missing suitable students? Med Educ Online 2016;21:29705.

Arlow JA, Brenner C. Psychoanalytic concepts and the structural theory. New York, NY: International Universities Press;1964.

Balint M. The doctor, his patient and the illness. 2nd ed. London: Churchill Livingstone; 1986.

Berg K, Blatt B, Lopreiato J, Jung J, Schaeffer A, Heil D, et al. Standardized patient assessment of medical student empathy: ethnicity and gender effects in a multi-institutional study. Acad Med 2015;90:105111.

Berg K, Majdan JF, Berg D, Veloski J, Hojat M. A comparison of medical students' self-reported empathy with simulated patients' assessments of the students' empathy. Med Teach 2011;33:388-391.

Bhagat V, Haque M, Simbak NB, Jaalam K. Study on personality dimension negative emotionality affecting academic achievement among Malaysian medical students studying in Malaysia and overseas. Adv Med Educ Pract 2016;7:341-346.

Bond M. Empirical studies of defense style: relationships with psychopathology and change. Harv Rev Psychiatry 2004;12:263-278.

Cho SH. A validation study of Korean version of Defense Style Questionnaire. Korean Journal of Counseling and Psychotherapy 1999;11:115137.

Fenichel O, Rangell L. The psychoanalytic theory of neurosis. New York, NY: W. W. Norton \& Company;1995. 
Garaigordobil M. A comparative analysis of empathy in childhood and adolescence: gender differences and associated socio-emotional variables. Rev Int Psicol Ter Psicol 2009;9:217-235.

Hardeman RR, Burgess D, Phelan S, Yeazel M, Nelson D, van Ryn M. Medical student socio-demographic characteristics and attitudes toward patient centered care: do race, socioeconomic status and gender matter? A report from the Medical Student CHANGES study. Patient Educ Couns 2015;98:350-355.

Hojat M, Gonnella JS, Nasca TJ, Mangione S, Vergare M, Magee M. Physician empathy: definition, components, measurement, and relationship to gender and specialty. Am J Psychiatry 2002;159:1563-1569.

Kam B, Oh YR, Lee SH, Roh HR, Hahm JR, Im SJ. Experience of clinical skills assessment in the Busan-Gyeongnam Consortium. Korean J Med Educ 2013;25:327-336.

La Cour P. Psychological defenses of Danish medical students. J Nery Ment Dis 2002;190:22-26.

Lee BK, Bahn GH, Lee WH, Park JH, Yoon TY, Baek SB. The relationship between empathy and medical education system, grades, and personality in medical college students and medical school students. Korean J Med Educ 2009;21:117-124.

Lee SJ. The relationship of defense changes during clinical clerkship with physician-patient interactions, resilience, and circadian preference [dissertation]. Jinju: Gyeongsana National University;2018.

Lee SJ, Park CS, Kim BJ, Lee CS, Cha BS, Kang H. Circadian preference and defense in medical students: greater consumption and lesser sublimation predicting eveningness. Sleep Med Psychophysiol 2013; 20:82-87.

Lee SJ, Park CS, Kim BJ, Lee CS, Cha B, Lee JS, et al. Association between changes in chronotype during clerkship and defense style among medical students. Chronobiol Med 2019;1:32-39.

Lee SJ, Park CS, Kim BJ, Lee CS, Cha B, Lee YJ, et al. Psychological development during medical school clerkship: relationship to resilience. Acad Psychiatry 2020;44:418-422.

Lievens F, Ones DS, Dilchert S. Personality scale validities increase throughout medical school. J Appl Psychol 2009;94:1514-1535.

Lourinho I, Ferreira MA, Severo M. Personality and achievement along medical training: evidence from a cross-lagged analysis. PLoS One 2017; $12: \mathrm{e} 0185860$

Mahoney S, Sladek RM, Neild T. A longitudinal study of empathy in preclinical and clinical medical students and clinical supervisors. BMC Med Educ 2016;16:270.

Rezaei R, Mehrabani G. A comparison of the scorings of real and standardized patients on physician communication skills. Pak J Med Sci 2014;30:664-666.

Schreckenbach T, Ochsendorf F, Sterz J, Rüsseler M, Bechstein WO, Bender B, et al. Emotion recognition and extraversion of medical students interact to predict their empathic communication perceived by simulated patients. BMC Med Educ 2018;18:237.

Seitz T, Längle AS, Seidman C, Löffler-Stastka H. Does medical students' personality have an impact on their intention to show empathic behavior? Arch Womens Ment Health 2018;21:611-618.

Vaillant GE. Ego mechanisms of defense: a guide for clinicans and researchers. Washington, DC: American Psychiatric Pub;1992.

Waqas A, Rehman A, Malik A, Muhammad U, Khan S, Mahmood N. Association of ego defense mechanisms with academic performance, anxiety and depression in medical students: a mixed methods study. Cureus 2015;7:e337. 